\section{International Scientific Journal Theoretical \& Applied Science}

p-ISSN: 2308-4944 (print) e-ISSN: 2409-0085 (online)

Year: 2015 Issue: 04 Volume: 24

Published: $30.04 .2015 \quad$ http://T-Science.org
Sayyora Borievna Babarakhimova Assistant of the Department of the psychiatry, narcology, child psychiatry, medical psychology and psychotherapy Tashkent pediatric medical institute, Uzbekistan sayyora_barievna2010@bk.ru

Janneta Muhtarovna Iskandarova Assistant of the Department of the psychiatry, narcology, child psychiatry, medical psychology and psychotherapy Tashkent pediatric medical institute, Uzbekistan janneta-tvoya@mail.ru

SECTION 21. Pedagogy. Psychology. Innovations in the field of education.

\title{
THE MULTIMEDIA TECHNOLOGIES IN TEACHING OF PSYCHIATRY IN MEDICAL INSTITUTE
}

Abstract: The national educational standards for medical institutes include a significant reduction in the number of classroom hours for studying academic disciplines. It is impossible to present in detail all educational materials during class study hours. The experience in using the multimedia technology at the psychiatry has shown that the learning of educational material has become more intensive. It is important that the multimedia presentation can be played many times; the isolated schemes, video of the case study can be replayed. The article discusses the efficiency of multimedia technologies in teaching of psychiatry and their significance for the process of education.

Key words: multimedia technologies, process of education, psychiatry, medical institute.

Language: Russian

Citation: Babarakhimova SB, Iskandarova JM (2015) THE MULTIMEDIA TECHNOLOGIES IN TEACHING OF PSYCHIATRY IN MEDICAL INSTITUTE. ISJ Theoretical \& Applied Science 04 (24): $127-$ 130.

\section{Soi: http://s-o-i.org/1.1/TAS*04(24)20 Doi: crossef http://dx.doi.org/10.15863/TAS.2015.04.24.20 \\ МУЛЬТИМЕДИА ТЕХНОЛОГИИ В ПРЕПОДАВАНИИ ПСИХИАТРИИ В МЕДИЦИНСКОМ ИНСТИТУТЕ}

Аннотация: Национальные образовательные стандарты для медицинских институтов включают значительное сокращение часов для изучения академических дисииплин. Невозможно представить в деталях изучаемый материал в течение аудиторных часов. Опыт в использовании мультимедиа технологий в психиатрии показал, что изучение образовательного материала стало более интенсивныл. Важно, что мультимедиа презентации могут быть проиграны несколько раз; отдельные схемы, видео изучаемых случаев могут быть повторены. В статье обсуждается эффективность мультимедиа технологий в преподавании психиатрии и их значение для прочесса образования.

Ключевые слова: мультимедиа технологии, процесс образования, психиатрия, медицинский институт.

Увеличение форм, видов, объемов и источников информации, широкое распространение и быстрое совершенствование компьютерной техники и информационных технологий диктует необходимость смены приоритетов в высшем профессиональном образовании. Одним из приоритетных направлений процесса информатизации современного общества является информатизация образования - процесс обеспечения сферы образования методологией и практикой разработки и оптимального использования новых информационных технологий, ориентированных на реализацию психолого-педагогических целей обучения, воспитания. [3] Для повышения знаний и умений студентов необходимо привлечение в учебный процесс обучающих программ и новейших компьютерных технологий. Базы многих университетов имеют богатый выбор учебной литературы, но с учетом требований и специфики обучения в области медицины, важно проводить квалифицированный отбор учебной информации и форму ее презентации студентам. [1]. Информационные технологии имеют большой потенциал возможностей для совершенствования учебного процесса и повышения уровни подготовки будущих врачей. 
Одним из дидактических средств, обладающих развивающим потенциалом, является мультимедиа, позволяющая использовать текст, графику, видео и мультипликацию в режиме диалога, что расширяет области применения компьютера в учебном процессе. Согласно Г. Кирмайеру при использовании интерактивных мультимедийных технологий в процессе обученияю доля усвоенного материала может составить до 75\%. [5] Повышение эффективности усвоения учебного материала осуществляется за счет того, что мультимедиа представляют особый вид компьютерных технологий, которые объединяют в себе как традиционную статическую визуальную информацию (текст, графику), так и динамическую (речь, музыку, видеофрагменты, анимацию), обусловливая возможность одновременного воздействия на зрительные и слуховые органы чувств обучающихся, что позволяет создавать динамически развивающиеся образы в различных информационных представлениях (аудиальном, визуальном). [8] Зрительный канал по своим возможностям намного превосходит возможности всех других каналов восприятия информации человеком. В этой связи введение видеоинформация в учебнометодический материал для восприятия учебного материала, его усвоения и запоминания имеет исключительное значение. Аудиокомпоненты средств мультимедиа могут дополнять и обогащать видео фрагменты. Однако они могут иметь и важное самостоятельное значение, например, как средство активизации внимания, акцентирования на отдельные моменты излагаемого материала. [2] На основе анализа работ отечественных и зарубежных исследователей, педагогов, психологов было показано, что использование мультимедиа позволяет решить дидактические вопросы с большим образовательным эффектом, может стать средством повышения эффективности обучения, значительно сокращает время, отведенное на изучение обязательного учебного материала, дает возможность существенно углубить и расширить круг рассматриваемых проблем и вопросов [4].

Данная статья отражает опыт использования инновационных технологий на практических занятиях в преподавании такой дисциплины, как психиатрия. Обучение студентов проводится на 5 курсе. Для наиболее полного освоения предмета использовались электронные учебники, мультимедийные программы и обучающие видеофильмы. Используемые программы и фильмы обеспечивают высокую наглядность, т.к. студенты могут увидеть «классическую» клиническую картину основных психических заболеваний. Использование анимации в мультимедийных программах позволяет структурировать основные симптомы и синдромы, что вырабатывает у студентов навык правильной диагностики психической патологии.

Основной формой учебной деятельности являются семинарские занятия, их теоретическая часть определяет особенность применяемых мультимедиа программ, которые представлены в текстовом виде. К их числу отнесены электронные учебники, выписки из историй болезни, результаты психологического обследования больных, учебные пособия. На практической части семинарского занятия используются мультимедиа программы позволяющие использовать аудиовизуальную информацию для проблемного изложения изучаемого материала. Студентам ставится проблема и формулируются познавательные задачи, после чего с помощью мультимедиа программ обучающимся демонстрируется видео и аудиозаписи пациентов клиники. В ходе занятия фиксируются предложения и решения, выдвигаемые со стороны студентов по сформулированной проблеме. Демонстрация на экране с помощью мультимедийного проектора решений, предложенных студентами в процессе обсуждения. После систематизации полученных решений проводится общее обсуждение и выбирается рациональный вариант решения проблемы. Внедрение в учебный процесс информационных технологий позволяет использовать игровую методику преподавания для наиболее полного усвоения материала. На кафедре в учебный процесс вводится проведение текущего опроса по темам «Общей психопатологии» в виде имитации кибер-игры «Звездные войны». Методика рассчитана на 25-30 минут и используется для дополнительной оценки усвоения пройденного материала по темам «Психомоторные расстройства», «Расстройства воли и влечений» и «эмоциональные нарушения». Методика проведения занятия «Звездные войны»: педагог объясняет условия игры - на планету Земля вторгаются инопланетяне и захватывают студентов данной группы в плен с целью выяснения данных о психологических способностях человеческого организма и возможных отклонениях в психике людей. Преподаватель разбивает группу на 2 команды «инопланетяне» и «земляне». Команда «инопланетяне» должна выбрать из имеющегося аудиовизуального ряда все расстройства соответствующие теме и представить их команде «земляне», которые просматривают предоставленный материал, делят его на группы в соответствии с типологией расстройств, проводят классификацию представленных симптомов и синдромов. Полученные результаты 
выводятся на одном экране с помощью многооконного представления аудиовизуальной информации для общего заключения.

В ходе каждого занятия отведено время для решения ситуационных задач, которые проводятся с помощью базы данных видеоматериалов и выписок из историй болезни по всем основным темам изучаемого курса. В первые дни студентам демонстрируется видеоматериал, в котором представлена беседа больного с врачом, записи поведения больного в отделении. После чего предоставляются выписки из истории болезни, где отражены результаты основных методов исследования. Студенты проводят анализ полученного материала и делают заключение о патологии. По мере увеличения объема изученного материала, студентам демонстрируется только видеозапись, необходимые методы исследования обучающиеся выбирают сами, после чего получают выписку из истории болезни по выбранным методикам. На основании сделанного заключения проводят подбор методов лечения, обосновывают свой выбор и сравнивают с данными из истории болезни. К концу изучаемого курса студенты, под контролем педагога и лечащего врача, проводят опрос пациентов, назначают необходимые методы обследования и лечения. Таким образом, с помощью мультимедиа формируются навыки диагностики основных симптомов и синдромов психических расстройств, проведение дифференциального диагноза и постановка основного диагноза. Так же с помощью решения ситуационных задач студенты учатся выбирать наиболее рациональные методы исследования при различных психических патологиях и определять необходимый объем лечебных мероприятий.

Понятие «самостоятельная работа» многогранно. С самостоятельная работа одной стороны рассматривается как вид деятельности, стимулирующий активность, познавательный интерес, и как толчок к дальнейшему повышению квалификации, а с другой стороны - как система мероприятий или педагогических условий, обеспечивающих самостоятельную деятельность студентов на занятиях или во внеаудиторное время без непосредственного руководства, но под наблюдением преподавателя. [6] Основной задачей преподавателя становится создание условий, обеспечивающих нахождение, усвоение и переработку получаемой студентами информации за ограниченное время. В этой связи особую актуальность приобретают принципы организации самостоятельной работы студентов и их творческое осмысление [9]. Формирование готовности к решению различных проблем самостоятельной работы в широком контексте предполагает преподавание различных дисциплин более проблемно-ориентированными, использование рефлексивного подхода в обучении, стимулирование у студентов умения отражать свое видение проблемы путем формулирования собственных вопросов.[7] Использование информационных технологий в учебном процессе позволяет увеличить объем самостоятельной работы студентов. Для ее проведения сформирована база специальных учебно-методических пособий вспомогательного характера. Самостоятельная работа студентов направлена на первичное овладение знаниями. В процессе обучения для самостоятельной работы студентам дается задание - провести тестирование основных психических функций и личностных особенностей психически здоровых людей разных возрастных групп, используя электронную базу тестов. А затем подготовить презентацию, в которой отразить результаты работы по теме «Структура личности и ее способности». Под руководством педагога проводят анализ полученных результатов, сравнивают их с особенностями нарушений психических функций при различных психических заболеваниях. Также при организации самостоятельной работы студентов используются веб-квесты. Веб-квесты - «это деятельностно-ориентированная проектная дидактическая модель, предусматривающая самостоятельную поисковую работу учащихся в сети Интернет». [10] При организации самостоятельной работы с применением вебквестов, сначала определяется проблемная задача, определяется примерный перечень источников информации, продумывается процесс деятельности, и на конечном этапе - презентация результатов поисковой деятельности. Для вебквестов подбираются темы с учетом актуальные для современного общества «Наркомании», «Депрессии», «Психические расстройства при СПИД» и т.д.

Курс читался 6 группам, в которых занимается порядка 50 человек. По окончании курса студенты сдавали зачет. В группах, где занятия проводились с использованием мультимедийных технологий, показали более высокие результаты по всем формам зачета. Студенты из групп обучения с использованием мультимедиа технологий при зачетном тестировании набирали 85\% правильных ответов. В остальных группах правильных ответов по тестированию составило $65 \%$. Письменный экзамен по билетам в группах с традиционным методом преподавания был оценен на положительную оценку у $60 \%$ обучающихся, в группах с использованием инновационных технологий письменный экзамен был оценен на положительную оценку у $90 \%$ студентов. Более высокий уровень овладения практическими 
навыками также показали студенты из групп, где при отработке практических навыков использовались мультимедиа технологии.

Результаты работы показали, что на практических занятиях целесообразно использовать мультимедийные обучающие системы, направленные на структурирование полученных знаний и на отработку практических навыков по изучаемому курсу. Использование нескольких каналов чувственного восприятия и возможность включить учащегося в активную деятельность посредством применения продуктов и средств мультимедиа позволяют выработать и закрепить новые навыки и умения, полученные на занятиях, а также повысить эффективность и качество усвоения учебного материала за счет основных свойств мультимедиа-технологий.

\section{References:}

1. Bazhina IA (2010) Modulnoe obuchenie: tseli, struktura, rezultatyi /I.A.Bazhina/. V mire nauchnyih otkryitiy. № 4-2. Krasnoyarsk. pp. 81-83.

2. Voronov MV, Blinov AN, Pimenov VM (2000) Multimediynyie tehnologii $\mathrm{v}$ distantsionnom obuchenii. Sb. nauch. tr. «Obrazovanie i virtualnost» Harkov-Sevastopol. pp.149-153.

3. Gafurova NV, Churilova EY (2008) «Pedagogicheskoe primenenie multimediynyih sredstv». Uch. posobie - Krasnoyarsk . pp.7.

4. Egorova YN (1995) Multimedia v obrazovanii tehnologiya buduschego. Novyie tehnologii obucheniya, vospitaniya, diagnostiki i tvorcheskogo samorazvitiya lichnosti: Materialyi. Tretey Vserossiyskoy nauchno prakticheskoy konferentsii. - Yoshkar-Ola. pp.101-103.

5. Kirmayer G (1994) Multimedia. Moscow: Malip. pp.18-20.

6. Muhamedzyanova NA (2014) «Primenenie elektronnyih obuchayuschih programm kak uslovie povyisheniya kachestva obucheniya studentov». El. nauch. zhurnal «Informatsionnyie kommunikativnyie tehnologii $\mathrm{v}$ pedagogicheskom obrazovanii»
Available: http://journal.kuzspa.ru/articles/16/ (Accessed: 16.04.2015).

7. Rosina N (2006) Organizatsiya SRS v kontekste innovatsionnogo obrazovaniya. Vyisshee obrazovanie v Rossii. №7 Moscow. pp.109114.

8. Semenova NG (2005) Vliyanie multimedia tehnologiy na poznavatelnuyu deyatelnost i psihofizicheskoe sostoyanie obuchayuschihsya /N.G. Semenova, T.D. Boldyireva, T.N. Ignatova/. Vestnik OGU - Orenburg, №4. pp. 34-38.

9. Senashenko V (2006) Samostoyatelnaya rabota studentov: aktualnyie problemyi / V.Senashenko, N.Zhalnina // Vyisshee obrazovanie v Rossii., Moscow №7. pp. 103109.

10. Tarasevich EB (2009) Ispolzovanie veb-kvestov pri organizatsii samostoyatelnoy rabotyi uchaschihsya $\mathrm{v}$ obuchenii inostrannyim yazyikam. Mezhkulturnaya kommunikatsiya i professionalno orientirovannoe obuchenie inostrannyim yazyikam. Materialyi III Mezhdunarodnoy nauchnoy konferentsii, posvyaschennoy 88-letiyu obrazovaniya Belorusskogo gosudarstvennogo universiteta. Minsk, pp. 200. 